\title{
Exploration and Practice of Three Classroom Teaching Mode for Chinese Linguistic Literature Profession
}

\author{
Liwei Fu \\ School of Humanities and International Education, \\ Xi'an Peihua University, \\ Xi'an, Shaanxi 710125 \\ E-mail: 23728342@qq.com
}

\begin{abstract}
In order to address the contradiction between the traditional teaching mode and the employment of students, the School of Humanities and International Education in Xi'an Peihua University constructed a teaching pattern called Three Classrooms. With it, students will strengthen their theoretical knowledge in the first classroom, enhance varied capabilities in the second classroom and realize the unity of knowledge and practice. It was found that through the joint efforts of the Three Classrooms, the teaching performance was remarkably improved, lifting the talent cultivation onto a new stage.
\end{abstract}

Keywords-Chinese Linguistic Literature Profession; Three Classrooms; teaching

\section{INTRODUCTION}

As one of the firstly established majors in domestic universities, Chinese Linguistic Literature appeared at the end of the 19th century and has gained strong momentum since the reform and the opening up. Almost all comprehensive university, specialized institutions have set that major in the Department of Chinese or other departments. Among them, Peking University, Nanjing University and Renmin University of China are well-known as they have produced a large amount of talents specialized in Chinese. Ordinary colleges and universities also provide a great amount of graduates with excellent speaking and writing ability for primary and secondary schools and enterprises and institutions around the country. The Chinese Linguistic Literature Profession is classified into the teaching training type and the non-teacher training type which are different in the cultivation mode and orientation, yet with the similar curriculum such as Chinese Ancient Literature, Chinese Contemporary Literature, Foreign Literature, Ancient Chinese Language, Modern Chinese Language, Introduction to Linguistics and Aesthetics and Writing[1]. However, extensive courses contradict the current teaching indicators and social needs. The Three Classrooms can help deal with that as it is integrated with teachers' lecturing, on-campus activities and off-campus practice. With the three parts interacting with each other, students' comprehensive ability can be effectively improved.

\section{TEACHING DILEMMA OF CHINESE LINGUISTIC LITERATURE MAJOR}

Having been existed for a long time with profound bases, Chinese Linguistic Literature Profession boasts the relatively stable major courses, that is to say, the course content thirty years ago and after 30 years were similar. Objectively, the characteristics of the discipline itself restrict it to change professional learning. However, it is easy to find that, in today's rapid social development, there is a certain gap between the existing teaching content and teaching mode of Chinese Linguistic Literature and students' ability in the workplace. Therefore, schools and teachers have to deal with the difficulties in the teaching of this major.

\section{A. Rich content with limited time}

The courses of Chinese Linguistic Literature Profession belong to either the language or the literature [2]. The language courses include Modern Chinese Language, Ancient Chinese Language and Introduction to Linguistics, etc., involves the basic concept and basic theory which are in large number and hard to comprehend, such as the phonemes, lexicon of linguistics, whole sentences, casual sentence, analytic language, fusional language and so on. Students generally have difficulties in distinguishing the differences and relations between each other, which can be attributed to the historic and complexity of Chinese itself. Literature courses including Modern and Contemporary Chinese Literature, Ancient Literature and Foreign Literature, etc., covering thousands of works of hundreds of famous writers in all ages and from the east to the west, such as Li Bai, Du Fu, Bai Juyi, Lu Xun, Lao She, Shakespeare, Hugo. It can be seen that the content is very rich, which is a huge challenge to student's understanding ability, memory ability and appreciation of workd, but there is no doubt that these courses can help students lay a solid foundation for the future employment. Whether working as a primary and secondary school Chinese teacher, entering enterprises and public institutions as a clerk, or taking part in Civil Service Examinations, students have to master the necessary language skills and profound literary accumulation. However, according to the national curriculum standards, the total class hours the school can offer to students is extremely limited. The public and practical training courses are only about 2200 class hours in the whole four years, and 
professional courses only account for half of them. Therefore, this leads to the between the extremely rich teaching content and the limited class hour. Therefore, it is imperative for teachers to consider how to improve the teaching efficiency in a limited time.

\section{B. Strong theoretical significance with weak practical bases}

The teaching content of Chinese language and literature is relatively theoretical. For language courses, students are required not only to master basic theoretical knowledge comprehensively, but also to improve their oral and written expression abilities. Some students come from remote villages and their foundation of mandarin is poor while others are reluctant to express their own views or opinions in public due to introverted personality, who are all the objects that need the assistance of teachers. However, because of the limited class hours and a large number of students, teachers can only choose typical students in the classroom for one-to-one guidance and it is difficult to complete the tutoring and tone correction for every classmate, therefore the effect of practical teaching is greatly reduced. For the traditional literature classes, most of the content that students are required to master is mainly based on memory, analysis and thinking. Students are asked to clarify writers' works of different times and they not only need to appreciate classical literary works accurately but also to obtain the abilities to apply the abstract knowledge. Namely, literature courses emphasize more on the ideological and spiritual level. When discussing a writer's works, only student representatives can be allowed to speak on behalf of the whole class, which results in the low overall participation of students. Especially for students who have not been given the opportunity to express themselves for a long time, they may easily produce contradiction mentality. In addition, students need to transform knowledge into practical ability when they are employed. Whether they are teachers or clerks, students are required to present "brain" knowledge in the way of "mouth" or "hand". This demands teachers to explore methods to effectively shorten the distance between "classroom" and "workplace", so that students can use what they have learned.

\section{CONSTRUCTION AND IMPLEMENTATION OF THREE \\ CLASSROOMS TEACHING MODE FOR CHINESE LINGUISTIC LITERATURE MAJOR}

In order to achieve better teaching effect and cultivate more comprehensive talents, we not only need to be efficient in the classroom, but also be productive in the extracurricular time. In the past two years, the Chinese Linguistic Literature Profession in Xi'an Peihua University has dared to innovate, make bold attempts, integrate various effective resources, and construct the Three Classrooms teaching mode, which has achieved certain results.

First, let's look at what is the Three Classrooms. There are already some references for the term at home and abroad. Researchers generally agree on the understanding of the first classroom and the second classroom, but they do not completely agree on the view of the third classroom. Here, research and discussion are carried out by borrowing from the connotation of the Three Classrooms summarized by Li Lihui of Haikou College of Economics. The first classroom, namely classroom teaching, refers to all the courses completed in the classroom including theoretical courses, practical training courses, optional courses, etc. As far as Chinese Linguistic Literature major is concerned, the courses mentioned above are educational and teaching activities led by teachers, and the main task is to systematically impart the existing knowledge and experience in this field, requiring students to master basic linguistic and literary knowledge, and the results are expressed in scores. The second classroom means the extracurricular activities carried out in the school, including various activities organized by student associations and different competitions by schools and departments, which are the self-education activities that college students combine with their own specialties or self-demand, and the results are embodied by the quality and quantity of works and award-winning certificates. The third classroom represents off-campus practice, including students' part-time jobs in winter and summer vacations and internship with teachers as the guide. It is a social practical activity that students actively participate in, whose main task is to integrate their own specialties, enter the workplace in advance, accumulate work experience and test the effectiveness of self-learning, and the results are directly reflected in the evaluation of employers and instructors [3]. For the Chinese Linguistic Literature major, the Three Classrooms teaching mode is constructed, which can fully mobilize students' learning enthusiasm and initiative, combine on-campus and off-campus activities, effectively help students transform knowledge into practical ability, hence helping students adapt to the workplace better and faster.

\section{A. First Classroom: the only way to lay a solid foundation}

In addition to the compulsory ideological and political courses, English courses and physical education courses required by the state, we need to set up corresponding basic courses and compulsory courses in order to meet the needs of students' future employment, requiring students to master the knowledge points and subject systems that they will be able to use in the future, and consolidating the theoretical basis of students in the first classroom. Language courses can help students understand the basic knowledge and language rules of both modern and ancient Chinese, and grasp the general types and rules of language by comparison. The teaching of Chinese in the lower grades of primary schools focuses on literacy and writing. Teachers need to teach students the methods of reading and spelling of Chinese Pinyin, which requires the application of the major knowledge of modern Chinese course. At the higher grades of primary schools, especially at the middle school, classical Chinese has become the important teaching content, which needs to use the knowledge of ancient Chinese. Furthermore, the text of the Chinese lesson is a famous article or an excerpt of it at home and abroad, which requires students to have a solid literary foundation in order to correctly interpret works. Under the strict requirements of teachers, the basic content that students must memorize and master is indispensable, so do the Chinese talents in other positions. Therefore, guaranteeing the breadth and depth of the first classroom is the only way to consolidate students' theoretical basis.

\section{B. Second Classroom: an effective way to improve abilities}

With the development of society, college students nowadays show some different characteristics from those in the 
past. They are active, critical, versatile, willing to present themselves, independent, and not like being led by others. Therefore, it is difficult to meet students' learning needs by relying solely on the traditional "one classroom". [4] In order to stimulate students' enthusiasm for learning, we have built a learning platform of "second classroom", which not only enables students to show their abilities in all aspects, but also puts the learning of theoretical knowledge into specific practical activities, hence realizing "teaching by competition" and effectively improving students' comprehensive abilities.

In the first half of 2019, the Chinese Linguistic Literature major of the Chinese Department successfully organized a number of activities, such as three-stroke calligraphy contest, three-line poetry creation contest, classical reading contest and Chinese micro-class contest in primary and secondary schools, and carried out cultural exchanges between China and foreign countries on traditional festivals such as Shangsi Festival and Dragon Boat Festival. To become a qualified Chinese teacher in the future, we must get familiar with classical works and be able to read aloud with wonderful emotion and voice. we need to be able to write beautiful chalk, pen and brush characters, to explain the stroke order and structure rules of Chinese characters to students, and to create simple works, so as to give students a good demonstration of composition lessons. Under the background of the rapid development of science and technology, we can master and use new technology to make micro-lessons and carry out teaching. As an excellent secretarial staff, they need to have fluent writing and excellent expression skills, and be proficient in using common office software, etc. Therefore, every competition organized by schools and departments is not only an extension and test of classroom learning content, but also an elaborate design for students' abilities in the workplace. Through the competition, the excellent students can be affirmed and encouraged, and the average students can also observe the gap between themselves and others to quickly adjust their learning status and further work on improving their ability. Therefore, developing a diversified second classroom is an effective way to enhance students' abilities in all aspects.

\section{Third Classroom: a powerful way to unite understanding and action}

There is a saying in China: fake handle and a spout lip, which means that a person can only give lip service and his practical ability is weak, so he can only be an armchair strategist. Therefore, what we encourage is the integration of knowledge and practice, which shows that this person boasts solid foundation of theory and practice and he is the kind of competent and well-trained people. This is what the "unity of knowledge and practice" means. As for the cultivation of students, the lesson is also applicable. Teaching shouldn't stay at the theoretical stage and we can't simply improve students' abilities in one aspect. What we should do is to seek opportunities and build platforms for students to truly integrate theory with practice. [5]

On the one hand, with the help of teachers, students are required to take the initiative to find part-time jobs during the winter and summer holidays, actively exercise themselves, so that students are able to deal with different people in the society and complete simple tasks; on the other hand, $90 \%$ of the students choose the direction of Chinese and Chinese Education, so we should actively integrate resources inside and outside the school, sign practice units outside the school, and be led by teachers. On the premise of ensuring students' personal safety, we should allow students to go deep into the primary and secondary school classrooms, enter the classroom and contact with students and truly understand the knowledge and ability required by a teacher, so as to lay the foundation for future job hunting and employment.

In May 2019, more than 20 excellent students majoring in Chinese Linguistic Literature Profession in our school came to the rural primary schools in Fuping County, Shaanxi Province under the guidance of the instructors. In practice school, they combine what they have learned in college with the needs of primary school students. They repeatedly study textbooks and polish teaching plans. They learn systematically again, and then present it through a complete class from the methods of lecturing, the use of pronunciation and intonation to the writing of every chalk word and the production of every slide. Students also feel that only when they really stand on the three feet platform can they understand the importance of theoretical accumulation and practical exercise. It can be seen that the "third classroom" is a powerful way for students to integrate knowledge with practice.

\section{CONCLUSION AND REFLECTION}

At present, with the implementation of the Three Classroom teaching mode for Chinese Linguistic Literature Profession, certain progresses have been made, that is, students have more clear learning objectives, become more active in learning, and they have more free learning time, more flexible learning mode and more obvious learning effect. It can be said that the teaching of Chinese Linguistic Literature Profession is advanced, compared with the traditional teaching mode that teachers teach, students learn, and then participate in the final examination. At the same time, we also need to notice the drawbacks of the Three Classrooms. First of all, in the wave of the teaching reform, each course is making innovations and releasing diversified activities. However, as students' time is limited, 30\% students are perfunctory towards the course. What's more, the limited resources can only cover a small number of students, as only $10 \%$ students can get the internship opportunities, while others have no corresponding training opportunities. How to arrange the discipline activities and related events in the school? How to increase the students' internship opportunities? These are the issues need to be considered by experts and scholars. It is believed that under the joint efforts of the whole society, there will gradually be a balance between school education and the needs of employing unit, the talents training will also usher in a better future.[6]

\section{REFERENCES}

[1] Li Guiting. Professional Norms and Core Curriculum Standards for Chinese Linguistic Literature Major [M]. Jinan: Shandong People's Publishing House,2015,3(1).

[2] Fu Huijun, Zhan Meiying, Chen Qingsong. Teaching Reform and Research of Chinese Linguistic Literature Major in Normal Schools 
-Selected Works of Humanities Teaching [M].Hangzhou: Zhejiang University Press,2019.1(1).

[3] Li Lihui.The Third Classroom Theory of Applied Talents[J]. New Curriculum Research,2014(02):48-49.

[4] Sun Xiaoming, Zhang Hua. Three Paths for Approaching Classroom Talent Cultivation Through the Examples of Tourism Colleges-Taking Tourism College as an Example [J]. Journal of Jinzhou Medical University (Social Science Edition),2014(11):83-85.
[5] Li Yunhai, Xue Baolin. Exploration on the Innovative Education of Three Classroom Teaching Mode in Colleges and Universities [J]. Journal of Qiqihar Medical University,2008(29):855-856.

[6] Sun Jingyue. Three Classroom for Innovative Talent Cultivation in Finance and Economics Colleges [J]. Modern Economic Information,2013(09): 440. 